\title{
Kassandra em conto e teatro na virada do século XXI: reescrituras e leituras do mito
}

\section{Cassandra.}

\section{WOLF, Christa.}

Tradução de Marijane Vieira Lisboa.

São Paulo: Estação Liberdade, 1990. 145 p.

Christa Wolf, nascida em 1929, é considerada uma das mais proeminentes escritoras alemãs e, com certeza, de maior renome internacional. Sua obra foi traduzida para muitas línguas e recebeu inúmeras premiações. Seu conto Kassandra, ${ }^{1}$ de 1983, foi um grande sucesso internacional. Em quatro anos, já havia vendido mais de 500.000 exemplares; Wolf recebeu por essa obra o título de Doutor Honoris Causa da Universidade de Hamburg e da Ohio State University, além de vários outros prêmios importantes.

A autora publicou inclusive uma espécie de instrução para a interpretação de seu conto em forma de conferências, ${ }^{2}$ já que a narrativa é bastante complexa em sua estrutura formal, além de exigir um conhecimento prévio do enredo e dos principais personagens de alguns textos do literatura clássica grega que se reportam à Guerra de Tróia.

O grande sucesso da obra de Wolf se deve, certamente, ao fato de o público leitor haver identificado nessa releitura feita pela autora, acerca do mito de Kassandra, um vínculo com as questões sociopolíticas centrais que inquietavam o Ocidente no início dos anos 1980: a Guerra Fria e a busca por uma nova identidade para a mulher. 
Sobre a aproximação com o mito grego empreendida pela autora, essa afirmou em uma de suas conferências: "tudo isso começou, inocentemente, com uma pergunta que eu mesma me fiz: quem foi Kassandra antes que alguém escrevesse sobre ela?" (p. 278). Christa Wolf considera que os textos clássicos gregos trazem uma visão eminentemente masculina à tona. $\mathrm{E}$, de fato, a personagem havia sido descrita até então sempre a partir da perspectiva de homens, que, de uma maneira ou de outra, revestiram-na de sua visão de mundo, de sua imagem do feminino. Em seu conto, Christa Wolf procurou despir Kassandra dessa imagem, reescrevendo-a de uma nova perspectiva e dando visibilidade, assim, a um dos segmentos sociais historicamente oprimidos, o das mulheres.

Tomando como fontes a llíada, de Homero, e a Oréstia, de Ésquilo, Wolf eleva Kassandra à personagem central em sua reescritura do mito, uma mulher em busca da autonomia. A Kassandra de Wolf é uma mulher que não aceita passivamente o papel que the é imposto pela sociedade troiana, vai em busca de sua libertação, por meio do cargo de sacerdotisa e do dom da vidência. "Por que eu quis o dom da profecia a qualquer preço? Falar com minha própria voz: o bem supremo. Não desejei mais nada" (p. 14). Ao longo da leitura do conto acompanha-se o doloroso processo de busca de Kassandra por autoconhecimento e autonomia. E ela só alcança-os no momento de sua morte, em frente aos portões de Micenas, prisioneira de Agamenon, onde reconhece a si mesma com todas as suas fraquezas, aprendendo, inclusive, a encarar o seu medo de frente. Aí também rompe com o papel tradicional de vidente como uma espécie de porta-voz dos deuses, dizendo ao auriga: "Não creio que eu saiba de tudo. Quem sabe, no futuro, possam existir homens que saibam transformar suas vitórias em vida". $E$, um pouco antes, ao despedir-se de Enéias, já havia dito: "Se eu lhes disser que não sei nada, não vão me [Sic!] acreditar. Se disser o que prevejo, do que qualquer um seria capaz, matam-me" (p. 123). A sua vidência, portanto, resume-se ao que "qualquer um seria capaz" de ver desde que alcance essa autonomia, que ela deseja tanto a mulheres quanto a homens. Em sua terceira conferência Wolf conclui que

a autonomia é uma tarefa de todos, e as mulheres que se restringem aos valores femininos agem, a rigor, como thes foi ensinado: com manobras de despistamento, estão se esquivando às exigências que a realidade Ihes impõe enquanto pessoas, num sentido pleno (p. 123).

Fica claro, portanto, que, para Wolf, Kassandra não é a representação da vítima apenas por ser mulher, mas que as vítimas são todos aqueles, homens e mulheres, que, por não se reconhecerem capazes de falar, calam diante das barbáries do poder estabelecido.

Além de uma reescritura de Kassandra, Wolf despe tanto gregos quanto troianos de todo heroísmo. Aquiles, o grande herói grego e personagem central da llíada, recebe o epíteto "o animal". Agamenon, o grande comandante do exército grego, revela-se, ao longo do conto, um homem fraco, de baixa auto-estima. Kassandra não só prevê a derrota de Tróia, mas percebe e vai compreendendo, pouco a pouco, as artimanhas dos poderosos e toda a maquinação que constroem e legitimam a guerra. $\mathrm{E}$, à medida que percebe, denuncia $\mathrm{e}$, ao denunciar, vai se tornando incômoda, como filha do rei e profetisa. E o preço da denúncia é a perda dos privilégios e o início de seu longo e doloroso processo de emancipação da casa real e, principalmente, de autoconhecimento.

Wolf introduz também um relacionamento amoroso entre Kassandra e Enéias, um homem sensível e capaz de entendê-la, assim como Anquises, pai de Enéias, uma espécie de guru para Kassandra, que, junto com Arisbe e um grupo de mulheres de uma comunidade alternativa do monte Ida, longe do centro do poder troiano, ajuda Kassandra a libertar-se, pouco a pouco, de suas amarras palacianas.

Pouco antes de sua morte, prisioneira de Agamenon, Kassandra expressa o desejo de passar adiante o que aprendeu. Ela diz a Clitemnestra:

Dê-me apenas o mínimo para viver. Mas lhe imploro: mande-me um escriba, ou, melhor ainda, uma jovem escrava de excelente memória e boa voz. Permita-lhe que possa transmitir às suas filhas o que ouvirá de mim. Que por sua vez contarão às filhas e assim por diante. De modo que ao lado do rio de epopéias, esse minúsculo regato, a duras penas, possa também alcançar aqueles homens distantes, talvez mais felizes, que viverão um dia (p. 89).

A personagem de Wolf expressa aqui 0 anseio de mulheres, excluídas da história e da literatura, de reaprender a falar e a transmitir suas experiências. Seria, ao lado da história escrita por homens, do 'rio de epopéias', uma nova escritura, de uma perspectiva feminina. 
O grupo gaúcho de teatro Ói nóis aqui traveis foi criado em 1978 e apresenta uma proposta alternativa de teatro, denominado teatro de vivência; ele procura envolver os espectadores em suas peças, rompendo com a delimitação clássica entre palco e platéia. Também trabalha com o teatro de rua e uma escola de teatro popular, levando a arte para o meio do povo.

A peça Aos que virão depois de nós. Kassandra in Process surgiu, segundo o grupo, a partir da leitura da novela de Christa Wolf. Porém, integra também outras influências. Um DVD lançado pelo grupo ${ }^{3}$ e que apresenta, aproximadamente, um terço da peça, cuja duração é de três horas, dá uma boa idéia de como é a encenação. No disco de extras, que acompanham 0 referido DVD, os atores explicam sua proposta de teatro e falam a respeito do surgimento e da montagem da peça Kassandra in Process. ${ }^{4}$ Por meio do seu "teatro de vivência", o grupo não procura alcançar seu público somente pelo intelecto, porém, comunicar por uma via mais corporal, sensitiva, invocando imagens do inconsciente por uma linguagem simbólica e poética. O público fica muito próximo dos atores, sendo conduzido de um cenário para o outro numa enorme galeria que poderia lembrar a cidade de Tróia, na peça em questão. Assim, o grupo procura envolver o seu público de maneira mais orgânica de modo a despertar todos os sentidos, até mesmo o olfato e a gustação, levando os espectadores a vivenciar as cenas. Segundo os atores, é um teatro que propõe "uma relação mais próxima com a fisicalidade do mundo", como experimentam as crianças. Há, por exemplo, uma cena que representa uma reunião da comunidade alternativa do monte lda, na qual os personagens interagem de maneira muito direta com o público oferecendo-lhes uma bebida, um a um, de modo ritualístico. Por isso, o número de espectadores por apresentação também é bastante reduzido, em torno de 30 pessoas. Há ainda momentos em que eles fazem uso de línguas arcaicas, que o público a princípio não compreende, porém, à medida que vai se envolvendo com esses novos sons, vivencia-os e estabelece seus próprios significados, individualmente. Dessa forma, o público participa, segundo o grupo, da construção dos sentidos e de uma memória afetiva, e não só intelectual. Assim os atores acreditam estar deixando marcas aos que virão, por meio dessa vivência.

É também uma proposta de descontinuidade e de estranhamento, pois o grupo não segue um determinado texto à risca, quebra a unicidade de um discurso e de sua lógica interna, intercalando outros textos, envolvendo outras mentes falantes. Do texto de Christa Wolf tirou o esqueleto da idéia, acrescentando fragmentos de Heiner Müller, de sua peça Germânia 3 morte em Berlin, que apresenta um diálogo entre Stalin e Hitler. Essa é, para o grupo, a evocação de mais dois momentos de carnificina na história ocidental. Outro texto que se intercala é Que palavra será?, de Samuel Beckett. Há ainda um intercurso com Os lustos, de Albert Camus, além de citações de Allen Ginsberg, Eurípides, índios norte-americanos, George Orwell, Mahabharatha, Rimbaud, Pablo Neruda e Peter Handke. Na verdade trata-se, segundo o grupo de teatro, de evocações de uma mesma linhagem de pensadores de modo a criar uma lógica na descontinuidade.

A peça Kassandra in Process faz parte de um ciclo de encenações do grupo sobre mitos que pertencem ao imaginário do Ocidente. Considerando o mito como a memória da humanidade, ele procura trazê-lo para a vivência, para $\circ$ aqui e agora. $O$ grupo descreve a sua proposta de teatro a partir de dois mitos centrais: Fausto e Kassandra. O primeiro, por meio da idéia do descontentamento constante, da necessidade de manter-se correndo risco, indo sempre em busca de algo mais. E o segundo, pelo espírito pacifista e pelo confronto com 0 poder estabelecido: Kassandra como a voz do nosso tempo, como um olhar feminino sobre a guerra, por meio do qual se pode discutir essa questão que tanto aflige a humanidade. Essas seriam duas idéias básicas do Ói nóis aqui trveis, e o grupo acredita estar dando um passo ao mesmo tempo estético e político com essas encenações, um passo compartilhado com o público, para procurar evitar o caos da humanidade.

A leitura da novela de Wolf juntamente com a apreciação da peça do grupo Ói nóis aqui traveis evidenciam a assustadora atualidade da temática. Se nesta primeira década do século XXI a questão da Guerra Fria já tende a se esvair de nossa memória por causa da dissolução da União Soviética, o então pretenso 'inimigo do Ocidente', temos, na verdade, constantes renomeações para essa posição. A ainda sangrenta guerra do Iraque é o que se desfila diante de nós ao lermos o conto e assistirmos à peça. Algumas passagens evocam associações imediatas, a começar pela justificativa para a guerra, o rapto de 
Helena, na mitologia, o qual, na reescritura de Wolf, é denunciado como farsa. Kassandra diz:

Eu fui testemunha das idas e vindas entre o palácio e os sacerdotes do templo, das reuniões diurnas e noturnas do conselho, até que se fabricou uma notícia de impacto, bem martelada, polida como uma lança: Páris, o herói troiano, por ordem da nossa querida deusa Afrodite, raptara dos gregos fanfarrões Helena, a mais bela mulher da Grécia, para apagar a ofensa infligida daquela vez ao nosso grande rei Príamo, quando do rapto de sua irmã (p. 72).

O real motivo é a disputa pelo Helesponto, o ponto de acesso ao Mar Negro, controlado pelos troianos, e a presença de Helena em Tróia é pura fantasia. Em certo ponto, Kassandra descobre o que permanece encoberto aos troianos até o final, já que, naquele momento, ainda não desvencilhada de suas amarras emocionais ao palácio, não consegue gritar: "troianos, não temos nenhuma Helena!", mas, apenas, "estamos perdidos" (p. 76). A associação com a guerra do Iraque é inevitável: a desculpa para a invasão, a pretensa existência de um arsenal nuclear naquele país; na verdade, o interesse dos EUA pelo controle das fontes petrolíferas.

Outra associação possível do conto com a atualidade é a questão da 'construção' do inimigo. Kassandra consegue perceber as artimanhas discursivas:

E desde quando um oficial decidia sobre o uso de palavras? Desde que aqueles que se intitulavam 'do partido do rei' não viam mais no espartano Menelau um hóspede, mas um espião ou um provocador. O futuro inimigo. [...] Uma nova palavra. Em troca, abandonavase a antiga designação, hóspede. Mas palavras são apenas palavras. E todos os que insistiam em manter a expressão 'hóspede', inclusive eu, tornavam-se suspeitos de uma hora para outra (p. 63).

A passagem evoca a expressão 'eixo do mal' difundida nos primeiros anos de nosso século. Há também no conto vários eufemismos empregados para nominar a guerra. Kassandra relembra: "Mas não se devia chamar aquilo propriamente de guerra. De acordo com a linguagem oficial, tratava-se de uma agressão" (p. 78) apenas, termo este não tão distante dos atuais 'ocupação do Iraque' em vez de 'invasão', ou, melhor ainda, 'Operação Iraque Livre', ou ainda a contradição em termos 'guerra pela democracia e pela paz mundial'. A propósito, Wolf menciona, em suas conferências sobre Kassandra, algumas expressões relativas à Guerra Fria, como "equilíbrio nuclear" e "preparativos defensivos" (p. 244), que se encontram dentro dessa mesma lógica.

Ainda chama a atenção no conto da humilhação sádica do inimigo derrotado. Por exemplo, quando Aquiles arrasta o corpo morto de Heitor ao redor dos muros de Tróia ou também no enfrentamento de Pentesiléia, rainha das Amazonas, com Aquiles, quando este não só a mata, mas a violenta depois de morta. Kassandra diz: "Os homens fracos, sequiosos de vitórias, necessitam de nós como vítimas, para que se sintam vitoriosos" (p. 127). A necessidade de humilhar covardemente os derrotados também é algo presente em nossos dias. Os ecos de Abu Ghraib e da base militar de Guantánamo ainda ressoam em nossos ouvidos.

Poderíamos buscar o porquê desse desvio da autora pelo mito se as questões abordadas são tão atuais. Em primeiro lugar, a volta ao mito é uma característica marcante da literatura do século XX, conforme atesta, por exemplo, o conhecido estudo de Mielietinski. O teórico russo define essa recorrência ao mito na literatura moderna como "uma poética da mitologização, baseada na interpretação da cultura contemporânea por meios mitologizantes", ${ }^{5}$ apontando Thomas Mann e Joyce como seus pioneiros. ${ }^{\circ}$ Essa poética serve, segundo Mielietinski, não somente para organizar a narrativa mas também "de meio de descrição metafórica da situação da sociedade moderna [...] com o auxílio de paralelos dos mitos tradicionais, gerados por outro estágio do desenvolvimento histórico". ${ }^{7}$ Wolf situa-se, sem dúvida, nessa tradição não só com o conto Kassandra mas também com o seu romance posterior, Medeia, vozes.

Em segundo lugar, e talvez este seja o ponto mais relevante aqui, Wolf volta às fontes fundadoras da nossa cultura ocidental patriarcal marcada por uma narração histórico-literária do ponto de vista dos vencedores, ou seja, dos grandes heróis masculinos, e reverte essa escritura, por assim dizer, ao introduzir uma outra perspectiva que o grupo Ói nóis aqui traveis interpreta como "um olhar feminino sobre a guerra".

Nas palavras de Wolf, ela objetiva, com a figura de Kassandra, "a partir do mito, recuperar as coordenadas sociais e históricas" (p. 259). Seria um trabalho "arqueológico e utópico ao mesmo tempo: desenterrar uma figura mitológica e traçar o esboço de um modelo social". ${ }^{8}$ Wolf parte do pressuposto de que 
a epopéia, surgida na luta pelo patriarcado, será também, por meio de sua própria estrutura, um instrumento para o estabelecimento e a consolidação daquele último. Impõe-se ao herói o papel de modelo exemplar, até hoje em dia. O coro das mulheres desaparece, é tragado pela terra. A mulher só pode ser heroína, daí em diante, enquanto objeto da narrativa masculina (p. 299-300).

A historiografia literária tem sido alvo de diversos estudos feministas, como, por exemplo, o da teórica francesa Ria Lemaire. Em seu ensaio "Repensando a história literária", ela lembra igualmente o papel determinante da escrita na monopolização da cultura masculina e uma "progressiva marginalização, deformação e obliteração das tradições orais femininas".9 Portanto, trazer à consciência presente, por meio da reescritura, figuras mitológicas consagradas pelas epopéias e tragédias antigas significaria um processo de reversão de estruturas naturalizadas pelo tempo; representaria um questionamento da nossa sociedade capitalista ocidental a partir de suas raízes, pois, conforme observa a teórica alemã Stephanie Risse, "a emancipação e a auto-consciência só podem se dar a partir do rompimento com estruturas internalizadas". ${ }^{10}$

E, assim, a voz pacifista da escrava-autora se impõe como um registro, muito embora tímido diante dos discursos oficiais regidos pela lógica da guerra, mesmo que representando apenas um minúsculo regato ao lado do rio de epopéias que, porém, conforme também quer - Oi nóis aqui aqui traveis, talvez alcance os que virão depois de nós.

\section{Notas}

1 Na tradução para o português, Marijane Vieira Lisboa emprega a designação 'novela' para o texto de Wolf, possivelmente por sua extensão - 145 páginas - e grande número de personagens.

${ }^{2}$ Christa WOLF, 1993. Na publicação brasileira, as conferências integram o livro juntamente com o conto.

${ }^{3}$ AOS QUE VIRÃO depois de nós..., [19"?].

' Baseio-me neste 'bate-papo' dos atores, gravado no disco de extras do referido DVD, para a exposição que se segue.

${ }^{5}$ Eleasar MIELIETINSKI, 1987, p. 426.

${ }^{6}$ MIELIETINSKI, 1987.

${ }^{7}$ MIELIETINSKI, 1987, p. 441.

${ }^{8}$ WOLF apud Bernd MATZKOWSKI, 1996, p. 12.

${ }^{9}$ Ria LEMAIRE, 1994, p. 68.

${ }^{10}$ Stephanie RISSE apud MATZKOWSKI, 1996, p. 17.

\section{Referências bibliográficas}

AOS QUE VIRÃO depois de nós. Kassandra in Process "A criação do horror. Coprodução da Terreira da Tribo e Catarse “ Coletivo de Comunicação. Patrocínio da Petrobrás. DVD duplo. Porto Alegre, [19"?].

LEMAIRE, Ria. "Repensando a história literária". In: HOLLANDA, Heloísa Buarque de (org.). Tendências e impasses. O feminismo como crítica da cultura. Rio de Janeiro: Rocco, 1994. p. 58-71.

MATZKOWSKI, Bernd. Erläuterungen zu Christa Wolf. Kassandra. Hollfeld: C. Bange Verlag, 1996.

MIELIETINSKI, Eleasar M. A poética do mito. Tradução de Paulo Bezerra. Rio de Janeiro: Forense Universitária, 1987.

WOLF, Christa. Voraussetzungen einer Erzählung: Kassandra. München: dtv, 1993.

Rosvitha Friesen Blume Universidade Federal de Santa Catarina 